\section{Survey of Nutrition Management Practices in Centers for Pediatric Intestinal Rehabilitation}

\author{
Anita M. Nucci, PhD, RD, LD ${ }^{1}$; Kipp Ellsworth, MS, RD, CSP, CNSC ${ }^{2}$; \\ Austin Michalski, RD, LD, CNSC ${ }^{3}$; Emily Nagel, MS, RD, $\mathrm{CNSC}^{4}$; \\ and Jackie Wessel, MEd, RD, CNSC, CSP, CLE; \\ on behalf of the ASPEN Pediatric Intestinal Failure Section
}

Volume 33 Number 4

August 2018 528-538

(C) 2017 American Society for

Parenteral and Enteral Nutrition

DOI: $10.1177 / 0884533617719670$

wileyonlinelibrary.com

WILEY

\begin{abstract}
Background: Nutrition management of pediatric intestinal failure (IF) requires interdisciplinary coordination of parenteral nutrition (PN) and enteral nutrition (EN) support. Nutrition strategies used by specialists in pediatric intestinal rehabilitation to promote gut adaptation and manage complications have not been previously summarized. Methods: A practice survey was distributed to members of the dietitian subgroup of the American Society for Parenteral and Enteral Nutrition Pediatric Intestinal Failure Section. The survey included 24 open-ended questions related to PN and enteral feeding strategies, nutrition management of PN-associated liver disease, and laboratory monitoring. Results: Dietitians from 14 centers completed the survey. Management components for patients at risk for cholestasis were consistent and included fat minimization, trace element modification, avoiding PN overfeeding, and providing EN. Parenteral amino acid solutions designed for infants/young children are used in patients $<1$ or 2 years of age. Trace minerals are dosed individually in 10 of 14 centers. Eleven centers prescribe a continuous infusion of breast milk or elemental formula 1-2 weeks after resection while 3 centers determine the formula type by the extent of resection. Most $(86 \%)$ centers do not have a protocol for initiating oral/motor therapy. Laboratory panel composition varied widely by center. The selection and frequency of use depended on clinical variables, including cholestatic status, exclusive vs partial PN dependence, postrepletion verification vs routine monitoring, intestinal anatomy, and acuity of care. Conclusion: EN and PN management strategies are relatively consistent among U.S. centers. Collaborative initiatives are necessary to define better practices and establish laboratory monitoring guidelines. (Nutr Clin Pract. 2018;33:528-538)
\end{abstract}

\title{
Keywords
}

enteral nutrition; liver failure; parenteral nutrition; pediatrics; short bowel syndrome; surveys and questionnaires

Short bowel syndrome (SBS) may occur after massive resection of the small bowel due to necrotizing enterocolitis or conditions such as small bowel atresia, malrotation with midgut volvulus, or gastroschisis and is the most common cause of intestinal failure (IF) in children. ${ }^{1}$ IF can also occur due to impaired intestinal absorption or altered motility in children with microvillus atrophy or intestinal pseudo-obstruction. Pediatric IF is a clinical condition characterized by malabsorption, malnutrition, and growth retardation. ${ }^{2-4}$ Management of children with IF is complex but can be optimized by interdisciplinary coordination of nutrition support, medical therapies, and surgical interventions. ${ }^{5}$ Many children with IF experience progressive adaptation of their remaining small bowel over a few months to years with eventual independence from parenteral nutrition (PN). However, hepatobiliary disease is a chronic complication of long-term use of PN and is a major contributor to the high morbidity and mortality of children with IF. ${ }^{5,6}$ Nutrition management during the period of intestinal adaptation includes maintenance of fluid and electrolyte balance as well as enteral nutrition (EN) and PN support. ${ }^{7}$ Pediatric nutrition specialists rely on established nutrition guidelines and interventions intended to promote adaptation of the remnant small bowel and facilitate weaning of PN and achievement of enteral autonomy before complications occur. ${ }^{8}$

From ${ }^{1}$ Georgia State University, Atlanta, Georgia, USA; ${ }^{2}$ Children's Healthcare of Atlanta, Atlanta, Georgia, USA; ${ }^{3}$ University of Michigan, C.S. Mott Children's Hospital, Grand Rapids, Michigan, USA; ${ }^{4}$ Helen DeVos Children's Hospital, Grand Rapids, Michigan, USA; and ${ }^{5}$ Cincinnati Children's Hospital Medical Center, Cincinnati, Ohio, USA.

Financial disclosure: None declared.

Conflicts of interest: None declared.

This article originally appeared online on July 21, 2017.

Corresponding Author:

Anita M. Nucci, PhD, RD, LD, Department of Nutrition, Georgia State University, PO Box 3005, Atlanta, GA 30302-3995, USA.

Email: anucci@gsu.edu 
Nutrition practice guidelines for the general management of children receiving PN have existed for several decades. ${ }^{9-11}$ In 2004, a 2-part review of intestinal rehabilitation (IR) and SBS management by DiBaise et $\mathrm{al}^{1}$ was published. Part I included an overview of the pathophysiology of SBS and a discussion of luminal nutrients, hormones, growth factors, and other substances that may enhance adaptation. Part II provided nutrition management guidelines for SBS with dietary guidelines by the presence or absence of a colon, suggestions for micronutrient supplementation, and a discussion of the clinical benefits of management by an interdisciplinary IR team. ${ }^{5}$ More recently, detailed macronutrient and micronutrient recommendations for the management of children with IF have been published. These reports include initial postoperative as well as short-term and long-term PN and EN recommendations and laboratory monitoring guidelines ${ }^{12,13}$ with an emphasis on the prevention of nutrient deficiencies and complications, such as IF-associated liver disease (IFALD). ${ }^{14}$ In addition, multiple cohort studies have reported benefits of restricting intravenous (IV) soy-based fats as a means of preventing IFALD,${ }^{15}$ as a treatment for infants diagnosed with IFALD,${ }^{16}$ and after reversal of cholestasis using fish oilbased IV emulsion. ${ }^{17}$ Although clinical nutrition guidelines for the management of children with IF are available, most research that has been conducted in this population has been descriptive or semi-experimental in design. Clinical trials are costly and often require multicenter collaboration to obtain an adequate sample size. However, experimental studies to establish evidence-based criteria for care are needed. ${ }^{12}$ No published review of current nutrition practice for this population has been reported. The purpose of this study is to (1) summarize the nutrition strategies used by physicians and dietitians in pediatric IR to promote gut adaptation and manage complications in children with IF and (2) compare current nutrition practice with existing recommendations.

\section{Methods}

The Pediatric Intestinal Failure Section of the American Society for Parenteral and Enteral Nutrition (ASPEN) was initiated in 2014. The section includes physician, dietitian, and pharmacy subgroups. The dietitian subgroup includes members from 27 pediatric hospitals within the United States and 4 international facilities. The short-term goals of the dietitian subgroup are (1) to prepare nutrition education materials for use by healthcare professionals and caregiver(s) of children with IF and (2) to create a network of practitioners with a specialty in pediatric IF for the purpose of sharing resources and discussing nutrition practice issues. A long-term goal of the subgroup is to develop nutrition research questions and form multicenter research collaborations. A qualitative nutrition practice survey developed by the dietitian subgroup was electronically distributed to all subgroup members between January and September 2015. The survey included 23 primarily open-ended questions related to IR center composition, PN and enteral feeding strategies, nutrition management of IFALD, and laboratory monitoring (Table 1). The study was determined to be exempt from federal regulations by university institutional review boards.

\section{Results}

\section{IR Center Structure}

Dietitians from 14 centers completed the survey. The centers were located in Atlanta, Georgia; Aurora, Colorado; Baltimore, Maryland; Boston, Massachusetts; Cleveland, Ohio; Cincinnati, Ohio; Columbus, Ohio; Grand Rapids, Michigan; Indianapolis, Indiana; Little Rock, Arkansas; New Haven, Connecticut; St Louis, Missouri; and Seattle, Washington. Seven of the 14 centers $(50 \%)$ have an organized interdisciplinary IR service that manages children with IF upon discharge from the neonatal intensive care unit (NICU). While in the NICU, children with IF are managed by the NICU service with consultation from the IR team. Centers without an organized IR team use both the gastroenterology and pediatric surgery services for care management.

\section{PN Management}

Parenteral amino acid solutions designed for infants and young children are used in patients $<1$ year of age in all but 1 center, which uses the product up to 2 years of age. A standard parenteral amino acid solution is used thereafter. Twelve of 14 centers $(86 \%)$ include protein calories when calculating total caloric intake. While excluding protein calories when calculating total caloric intake has not been a standard of care for many years, we assessed whether dietitians working in IR centers still follow this practice. The general practice of dosing trace elements and cycling/tapering of PN solutions is shown in Table 2. Eleven of the 14 centers $(79 \%)$ reported monitoring serum levels of trace elements as a result of reduced intake, specifically copper, selenium, and zinc. Dietitians from 10 centers reported that the decision to initiate iron supplementation is dependent upon laboratory determination of deficiency. The general consensus was that enteral iron should be provided when there is a sufficient length of proximal small bowel and tolerance to enteral feedings is established. IV iron is selected in the case of an extremely short bowel and feeding intolerance where PN is the primary source of nutrition. PN support standards of care did not significantly differ for children who receive long-term PN ( $>1$ month) at the centers surveyed. However, 4 center dietitians $(29 \%)$ noted that laboratory monitoring differed by the length of time on PN with the inclusion of parameters for 
Table 1. Pediatric Intestinal Failure Nutrition Practice Survey Questions.

\begin{tabular}{|c|c|}
\hline Number & Question \\
\hline 1 & What medical services/teams manage your patients with IF? \\
\hline 2 & What is your standard protein source for PN? \\
\hline 3 & Do you use the same protein source for all patients (yes/no)? \\
\hline 4 & $\begin{array}{l}\text { If you use the same protein source for all patients, under what circumstances would you use a specialized } \\
\text { parenteral amino acid solution? }\end{array}$ \\
\hline 5 & Do you use a trace mineral package or dose minerals individually for patients on PN? \\
\hline 6 & For patients with IF on PN, when would you provide supplemental iron? \\
\hline 7 & If supplemental iron is provided, how is it given and under what circumstances would each method be chosen? \\
\hline 8 & Do you have any protocols for patients receiving long-term ( $>1$ month) PN without EN intake? \\
\hline 9 & Do you include protein calories when calculating the caloric intake of patients on PN? \\
\hline 10 & What is your practice regarding cycling PN? \\
\hline 11 & What is your practice regarding tapering of $\mathrm{PN}$ ? \\
\hline 12 & $\begin{array}{l}\text { If you are caring for a patient with IF who is at risk for cholestasis, what is your general philosophy for } \\
\text { nutrition management? }\end{array}$ \\
\hline 13 & $\begin{array}{l}\text { If you are caring for a patient with IF who has cholestasis, what is your standard practice for nutrition } \\
\text { management? }\end{array}$ \\
\hline 14 & $\begin{array}{l}\text { If you are caring for a patient with cholestasis, what is your institution policy with regard to the provision of } \\
\text { parenteral trace minerals? }\end{array}$ \\
\hline 15 & How many days are your patients with IF typically ordered "nothing by mouth" status post resection? \\
\hline 16 & What is your formula of choice for children with IF status postresection? \\
\hline 17 & What is your typical mode of feeding after resection? \\
\hline 18 & What oral supplements do you typically recommend for patients with IF? \\
\hline 19 & Do you have a protocol for starting oral/motor therapy for oral feedings after resection? \\
\hline 20 & How soon are oral feedings initiated in children with IF at your center? \\
\hline 21 & Do you use urine sodium to determine whether a patient with IF requires sodium supplementation? \\
\hline 22 & $\begin{array}{l}\text { What laboratory tests do you routinely follow in patients with IF on PN? Include macronutrients and } \\
\text { micronutrients and interval for follow-up (eg, daily, weekly, monthly). }\end{array}$ \\
\hline \multirow[t]{7}{*}{23} & Which of the following parameters do you follow in patients receiving PN? \\
\hline & a. Carbohydrate infusion rate (select: $\mathrm{mg} / \mathrm{kg} / \mathrm{min}$ or $\mathrm{mg} / \mathrm{kg} / \mathrm{h}$ ) \\
\hline & b. Serum triglyceride \\
\hline & c. Serum cholesterol \\
\hline & d. Triene/tetraene ratio \\
\hline & e. Nonprotein nitrogen/calorie ratio \\
\hline & f. Other: \\
\hline
\end{tabular}

EN, enteral nutrition; IF, intestinal failure; PN, parenteral nutrition.

trace elements and essential fatty acid deficiency to the monitoring schedule for those on long-term PN.

\section{Enteral/Oral Management}

Eight of the center dietitians (57\%) reported a length of time that children with IF are typically unable to receive enteral/oral feeding after initial surgery (range, 5 days to 2 weeks). The type of EN and oral supplementation provided to children with SBS after resection varied between centers (Table 3). Most centers $(n=13)$ prefer the administration of continuous feeds via nasogastric tube $(\mathrm{NG})$ or gastrostomy tube (GT) postresection, with 2 also recommending small oral feedings as tolerated. One center prefers to provide oral feeding in the absence of feeding intolerance and if the child is developmentally ready for oral intake. Vitamin, trace element, and fiber supplements are the products most commonly prescribed.
Most centers $(\mathrm{n}=12)$ do not have a formal protocol for the initiation of oral feedings after small bowel resection. Nine of these centers do consult with occupational or speech therapy for the purpose of encouraging ageappropriate complementary food intake when the child is developmentally ready. Two centers reported that they use a protocol for starting oral intake. Of these, 1 center begins with nonnutritive oral feedings of human milk or infant formula and advances to small-volume oral boluses when trophic feedings are tolerated. This center also initiates solid foods at 6 months of age beginning with vegetables followed by bananas, grains, meats, and fruit. The second center begins with 2 oral feedings per day under the supervision of an occupational or speech therapist when enteral feedings have reached $3 \mathrm{~mL} / \mathrm{h}$. The timing of initiation of oral feedings varies by center. Most centers did not report an exact time point for the initiation of feedings but all provided qualifications for initiation of oral feedings (Table 3). 
Table 2. Practice Responses to Questions Related to Parenteral Nutrition Management.

\begin{tabular}{|c|c|c|c|}
\hline Survey Question & Response Rate & Practice Response & $\begin{array}{c}\text { Number of Centers } \\
\text { per Response }\end{array}$ \\
\hline $\begin{array}{l}\text { Do you use a trace element } \\
\text { package or dose minerals } \\
\text { individually for patients on } \\
\text { PN? }\end{array}$ & 14 of 14 & $\begin{array}{l}\text { - Trace element package only } \\
\text { - Individual dosing } \\
\text { - Both trace element package and individual } \\
\text { dosing are used }\end{array}$ & $\begin{array}{l}0 \\
9 \\
5\end{array}$ \\
\hline $\begin{array}{l}\text { What is your practice regarding } \\
\text { cycling of PN? }\end{array}$ & 11 of 14 & $\begin{array}{l}\text { Cycling criteria }^{\mathrm{a}} \\
\text { - } \quad \text { Medical stability } \\
\text { - } \quad \text { Minimum } 3 \text { months corrected age } \\
\text { - } \quad \text { Weight }>5 \mathrm{~kg} \\
\text { - Intake of }>50 \mathrm{kcal} / \mathrm{kg} / \mathrm{d} \text { from EN } \\
\text { - } \quad \text { Tolerance of continuous enteral feeding }\end{array}$ & $\begin{array}{l}6 \\
3 \\
1 \\
1 \\
1\end{array}$ \\
\hline & 14 of 14 & $\begin{array}{l}\text { Cycling strategy } \\
\text { - } 1 \text { - to 2-hour increments } \\
\text { - 2- to 4-hour increments } \\
\text { - No more than } 4 \text { hours off PN (infants) } \\
\text { - No specific strategy reported }\end{array}$ & $\begin{array}{l}3 \\
5 \\
1 \\
5\end{array}$ \\
\hline $\begin{array}{l}\text { What is your practice regarding } \\
\text { tapering of PN? }\end{array}$ & 14 of 14 & $\begin{array}{l}\text { Tapering strategy } \\
\text { - } \quad \text { minutes up and down } \\
\text { - } 30 \text { minutes up and } 1 \text { hour down } \\
\text { - } 1 \text { hour up and down } \\
\text { - } 2 \text { hours down only } \\
\text { - } \quad \text { hours up and down } \\
\text { - } \quad \text { No specific strategy reported }\end{array}$ & $\begin{array}{l}1 \\
1 \\
8 \\
1 \\
1 \\
2\end{array}$ \\
\hline
\end{tabular}

EN, enteral nutrition; $\mathrm{PN}$, parenteral nutrition.

${ }^{\text {a }}$ Centers may have reported $>1$ response.

\section{Prevention and Management of IFALD}

The center dietitians were queried regarding general philosophies toward the nutrition management of patients at risk for IFALD. Limiting IV fat was a major component of the nutrition management of children with IF at risk for developing cholestasis at all centers (Table 4). Among the centers employing some form of fat restriction, typical dosing was limited to $1-2 \mathrm{~g} / \mathrm{kg} / \mathrm{d}$. The second major theme among the centers participating in the survey was providing $\mathrm{EN}$ in the form of trophic feedings or aggressive advancement of feedings. Monitoring parameters included glucose infusion rate (GIR), triene/tetraene ratio, trace elements, and weight gain and linear growth. The center dietitians were also asked to describe their standard practice for the nutrition care of a child with IF as well as IFALD. Fat minimization or restriction is the most common element of nutrition support practice among all centers included in the survey (Table 4). Each center typically limits IV fat to 1 $\mathrm{g} / \mathrm{kg} / \mathrm{d}$ in patients with cholestasis. However, some centers $(\mathrm{n}=3$ ) reduce fat dose to $<1 \mathrm{~g} / \mathrm{kg} / \mathrm{d}$ either by providing a restricted daily dose or providing $1 \mathrm{~g} / \mathrm{kg} 2$ or 3 days per week. Four dietitians reported that trace elements were dosed individually at their centers for children with IFALD.
Two centers provide a reduced amount of copper and 3 centers remove manganese entirely from the PN solution.

\section{Laboratory/Biochemical Monitoring}

An overview of the IF center dietitian practice survey responses to questions related to laboratory/biochemical monitoring in children with IF is shown in Table 5. Most centers $(93 \%)$ use urine sodium to determine whether a patient requires sodium supplementation. Dietitians from all centers listed a variety of panels, vitamins, trace elements, and miscellaneous laboratories whose selection and frequency of use appeared to depend largely on a patient's clinical variables such as noncholestatic vs cholestatic status, exclusive vs partial PN dependence, postrepletion verification vs routine monitoring, intestinal anatomy, and acuity of care (ie, NICU vs general floor vs outpatient). Dietitians from all centers use the GIR $(\mathrm{mg} / \mathrm{kg} / \mathrm{min})$ as a clinical parameter for patients receiving $\mathrm{PN}$.

\section{Discussion}

While the provision of $\mathrm{PN}$ has resulted in a reduced mortality rate for infants and children with IF, serious and 
Table 3. Practice Responses to Questions Related to Enteral/Oral Nutrition Management.

\begin{tabular}{|c|c|c|c|}
\hline Survey Question & $\begin{array}{l}\text { Response } \\
\text { Rate }\end{array}$ & Practice Response & $\begin{array}{c}\text { Number of Centers } \\
\text { per Response }\end{array}$ \\
\hline $\begin{array}{l}\text { What is your formula of choice } \\
\text { for children with intestinal } \\
\text { failure status postresection? }\end{array}$ & 14 of 14 & $\begin{array}{l}\text { - Human milk or elemental infant formula } \\
\text { - Amino acid-based infant formula } \\
\text { - Selection based on the extent of small bowel resection }\end{array}$ & $\begin{array}{l}8 \\
3 \\
3\end{array}$ \\
\hline $\begin{array}{l}\text { What oral supplements do you } \\
\text { typically recommend for } \\
\text { patients with intestinal } \\
\text { failure? }^{\text {b }}\end{array}$ & 14 of 14 & $\begin{array}{l}\text { - Vitamin and trace element supplements } \\
\text { - Carbohydrate/fat or fat modular } \\
\text { - Fiber supplements } \\
\circ \text { Green beans } \\
\circ \quad \text { Pectin } \\
\circ \quad \text { Other fiber supplements }\end{array}$ & $\begin{array}{r}13 \\
4 \\
2 \\
3 \\
3\end{array}$ \\
\hline $\begin{array}{l}\text { How soon are oral feedings } \\
\text { initiated in children with } \\
\text { intestinal failure at your } \\
\text { center? }\end{array}$ & 14 of 14 & $\begin{array}{l}\text { - As soon as possible } \\
\text { - Depends on stool/ostomy output } \\
\text { - Varies individually } \\
\text { - Within 7-10 days } \\
\text { - Medically stable for } 2 \text { weeks on EN } \\
\text { - Age appropriate ( }>37 \text { weeks) } \\
\text { - } \text { Aevelopmentally appropriate; } 2-3 \text { days after EN initiated } \\
\text { - After EN is initiated }\end{array}$ & $\begin{array}{l}4 \\
2 \\
2 \\
1 \\
1 \\
1 \\
1 \\
1 \\
1\end{array}$ \\
\hline
\end{tabular}

EN, enteral nutrition.

${ }^{a}$ Human milk or an elemental infant formula with significant resection; polymeric infant formula with minimal resection.

${ }^{\mathrm{b}}$ Centers may have reported $>1$ response.

potentially life-threatening complications may still occur as a result of long-term use of PN. Growth failure continues to be observed in a high percentage of children with IF, ${ }^{18}$ the risk of nutrient deficiencies has been shown to increase during the transition from $\mathrm{PN}$ to $\mathrm{EN},{ }^{19-21}$ and multiple years of PN therapy can result in the development of IFALD. ${ }^{14}$ The nutrition care of children with IF should be individualized based upon the intestinal anatomy and medical condition of each patient. The EN and PN management strategies reported by the pediatric IF practitioners who participated in this survey are relatively consistent. Only half of the dietitians surveyed function as part of an organized IR program. The strategies currently being used are designed to support intestinal adaptation and reverse or slow the progression of complications. However, clinical and laboratory monitoring practices vary considerably between centers. Collaborative initiatives such as the Pediatric Intestinal Failure Section of ASPEN are ideally suited to define better practices and establish monitoring guidelines through multicenter research efforts.

PN is an established treatment for children with IF that must be carefully managed to prevent or delay the development of PN-associated complications. ${ }^{22}$ Methods currently recommended for the prevention of IFALD include avoiding overfeeding, providing a balanced distribution of macronutrients in the PN solution, cycling the $\mathrm{PN}$ infusion, and providing EN as tolerated. ${ }^{23}$ All of the dietitians surveyed reported that cycling of the PN solution is a treatment goal in their practices and that advancement (reduction in PN infusion hours) is determined by blood glucose tolerance. Providing a dextrose solution over fewer hours may result in a GIR greater than what is currently recommended for children without cholestasis $(<12-14$ $\mathrm{mg} / \mathrm{kg} / \mathrm{min}){ }^{23}$ Therefore, monitoring for hyperglycemia or hypoglycemia is essential during the cycled infusion and while the infusion is off. Abrupt cessation of PN has been reported to be well tolerated in children $>2$ years of age. ${ }^{24}$ However, many children with IF are $<1$ year of age at the time of diagnosis. ${ }^{25}$ Tapering of the dextrose solution over 30-60 minutes before discontinuation may prevent rebound hypoglycemia and is a common practice reported by the dietitians who completed our survey.

Most centers provide human milk or amino acid-based infant formula as the primary source of nutrition for children with SBS. This practice aligns with recommendations from the current literature. In a retrospective medical record review of 30 neonates with SBS, Andorsky et $\mathrm{al}^{26}$ reported that the use of either human milk or an amino acid-based formula was associated with a shorter duration of PN. Human milk contains long-chain fatty acids, free amino acids such as glutamine, and growth factors that paired with immune-enhancing properties may assist in intestinal adaptation. An amino acid-based formula may decrease the duration of PN since it contains a high percentage of 
Table 4. Practice Responses to Questions Related to Prevention and Management of Intestinal Failure-Associated Liver Disease.

\begin{tabular}{|c|c|c|c|}
\hline Survey Question & Response Rate & Practice Response & $\begin{array}{c}\text { Number of Centers } \\
\text { per Response }\end{array}$ \\
\hline $\begin{array}{l}\text { If you are caring for a patient } \\
\text { with short bowel syndrome } \\
\text { who is at risk for cholestasis, } \\
\text { what is your general } \\
\text { philosophy for nutrition } \\
\text { management? }\end{array}$ & 14 of 14 & $\begin{array}{ll}\text { - } & \text { IV fat restriction } \\
\text { - } & \text { Initiate/advance EN } \\
\text { - } & \text { Cycle PN } \\
\text { - } & \text { Avoid overfeeding } \\
\text { - } & \text { Dose trace elements individually } \\
\text { - } & \text { Wean PN } \\
\text { - } & \text { Monitor serum levels of trace elements } \\
& \text { Provide parenteral protein at age-appropriate } \\
& \text { level }\end{array}$ & $\begin{array}{r}12 \\
9 \\
4 \\
4 \\
2 \\
2 \\
2 \\
1\end{array}$ \\
\hline $\begin{array}{l}\text { If you are caring for a patient } \\
\text { with short bowel syndrome } \\
\text { who has cholestasis, what is } \\
\text { your standard practice for } \\
\text { nutrition management? }\end{array}$ & 14 of 14 & $\begin{array}{l}\text { - IV fat restriction } \\
\text { - } \text { Initiate/advance enteral nutrition } \\
\text { - } \text { Cycle PN } \\
\text { - } \text { Dose trace elements individually } \\
\text { - } \text { Monide fish oil-based IV fat emulsion } \\
\text { - Avoid overfeeding } \\
\text { - Monitor for essential fatty acid deficiency } \\
\text { - } \text { (triene/tetraene ratio) } \\
\text { - } \text { Do not exceed maximum recommended glu- } \\
\text { cose infusion rate } \\
\text { - Provide enteral formula with higher MCT oil } \\
\text { content }\end{array}$ & $\begin{array}{r}12 \\
9 \\
6 \\
4 \\
4 \\
4 \\
2 \\
2 \\
\\
2 \\
1 \\
1\end{array}$ \\
\hline
\end{tabular}

EN, enteral nutrition; IV, intravenous; MCT, medium-chain triglyceride; PN, parenteral nutrition.

${ }^{\mathrm{a}}$ Centers may have reported $>1$ response.

long-chain fatty acids, which may promote mucosal adaptation. ${ }^{27}$ Although long-chain fatty acids promote adaptation and provide a source of essential fatty acids, medium-chain triglycerides are advantageous because they can be directly absorbed by enterocytes. Most amino acid-based formulas contain a mixture of long-chain and medium-chain triglycerides, which may explain why most centers prefer these formulas if human milk is not available. Some researchers argue that there is insufficient evidence to support 1 type of formula over another for patients with SBS. Ksiazyk et al ${ }^{28}$ conducted a prospective, randomized, crossover, double-blind study of 10 children receiving infant formula containing either hydrolyzed or intact protein. Children were trialed on each formula for 30 days (crossover on day 31), and nitrogen balance and lactulose/mannitol excretion ratio (to measure intestinal permeability) were evaluated on days 1, 31, and 61 of the study. The researchers reported that the 2 types of formula did not yield a significant difference in intestinal permeability, caloric/energy intake, weight gain, or nitrogen balance. However, feeding tolerance was not assessed, and all infants were receiving $30 \%$ of calorie intake from hydrolyzed enteral feeds before beginning the study protocol. In a review of published data relevant to feeding strategies in children with SBS, Olieman et $\mathrm{a}^{29}$ recommended the use of human milk or standard polymeric formula depending on the age of the child.

Most centers initiate continuous feedings postresection since they are believed to be better tolerated than bolus feeds and promote adaptation via continual saturation of the intestinal lumen. However, limited research evidence exists on the topic. A frequently cited study to support the use of continuous feeds was conducted by Parker et al ${ }^{30}$ over 30 years ago. The researchers reported that continuous feedings yielded a significant increase in body weight and enteral balance (enteral retention of formula and nutrients) compared with oral bolus feeds. Unfortunately, the sample size was very small $(n=9)$, and only 2 of the infants had SBS. A more recent randomized crossover study of nutrient absorption by mode of nutrition therapy (tube feeding alone, oral feeding alone, combination of tube and oral feeding) was conducted in adults with SBS $(n=15)$. Results revealed significantly greater absorption of protein, fats, and energy when a tube feeding was used alone or in conjunction with oral feeding compared with when oral feeding was used alone. $^{31}$ Although continuous feedings may be better tolerated and improve nutrient absorption, bolus feedings are desirable as they mimic the typical infant eating pattern and are therefore more physiological. Bolus feedings allow for 
Table 5. Practice Responses to Questions Related to Laboratory/Biochemical Monitoring.

\begin{tabular}{|c|c|c|c|}
\hline Survey Question & Response Rate & Practice Response & $\begin{array}{c}\text { Number of Centers } \\
\text { per Response }\end{array}$ \\
\hline $\begin{array}{l}\text { Do you use urine sodium to determine } \\
\text { whether a patient with short bowel } \\
\text { syndrome requires sodium } \\
\text { supplementation? }\end{array}$ & 14 of 14 & $\begin{array}{l}\text { - Yes } \\
\text { - Yes, occasionally } \\
\text { - Yes, as well as serum osmolarity } \\
\text { - } \text { No }\end{array}$ & $\begin{array}{r}10 \\
2 \\
1 \\
1\end{array}$ \\
\hline $\begin{array}{l}\text { What laboratory tests do you routinely } \\
\text { follow in patients on PN with short } \\
\text { bowel syndrome or intestinal failure? } \\
\text { Include macronutrients and } \\
\text { micronutrients and interval for } \\
\text { follow-up (eg, daily, weekly, } \\
\text { monthly). }\end{array}$ & 13 of $14^{b}$ & $\begin{array}{l}\text { Panels (daily to monthly): CBC, CMP, } \\
\text { BMP } \\
\text { Vitamins (every 3-12 months): serum } \\
\text { retinol, retinol binding protein, RBC } \\
\text { folate, vitamin B-12, methylmalonic } \\
\text { acid, vitamin D, vitamin E } \\
\text { Trace elements (every 3-12 months): } \\
\text { serum copper, serum zinc, selenium } \\
\text { (RBC and serum), serum iron, total } \\
\text { iron binding capacity, ferritin } \\
\text { Other (every 3-12 months): magnesium, } \\
\text { phosphorous, serum triglycerides, C- } \\
\text { reactive protein, prothrombin time, in- } \\
\text { ternational normalized ratio, thyroid- } \\
\text { stimulating hormone, serum citrulline, } \\
\text { triene/tetraene ratio }\end{array}$ & $\begin{array}{l}\text { Varying responses } \\
\text { by } 13 \text { centers }\end{array}$ \\
\hline $\begin{array}{l}\text { Which of the following parameters do } \\
\text { you monitor in patients receiving } \\
\text { PN? } \\
\text { A. Glucose infusion rate } \\
\text { B. Serum triglyceride } \\
\text { C. Serum cholesterol } \\
\text { D. Triene/tetraene ratio } \\
\text { E. Nonprotein calorie/nitrogen ratio }\end{array}$ & 13 of $14^{b}$ & $\begin{array}{l}\text { - Glucose infusion rate } \\
\text { - Serum triglyceride } \\
\text { - Serum cholesterol } \\
\text { - Triene/tetraene ratio } \\
\text { - Nonprotein calorie/nitrogen ratio }\end{array}$ & $\begin{array}{r}14 \\
13 \\
4 \\
12 \\
5\end{array}$ \\
\hline
\end{tabular}

BMP, basic metabolic panel; CBC, complete blood count; CMP, comprehensive metabolic panel; PN, parenteral nutrition; RBC, red blood cell.

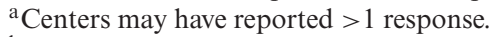

${ }^{\mathrm{b}}$ Question was not answered by 1 center.

periods of fasting, which may prevent hyperinsulinemia ${ }^{32}$ and promote appropriate bacterial clearance. ${ }^{33}$

Vitamins and trace elements were the supplements most often reported to be prescribed. Several dietitians also reported use of a carbohydrate and fat modular product, purees, and pectin/fiber. Vegetable oils such as canola, safflower, or flaxseed can be added to tube feedings to increase caloric intake or supplement essential fatty acids without adding significant volume. Fiber is often added to feedings to slow bowel transit time and reduce stool output, which assists with nutrient absorption and subsequently growth. ${ }^{34}$ Soluble fiber is beneficial because it is fermented into short-chain fatty acids, which can be metabolized by colonocytes for energy. ${ }^{35}$ In a 2010 practice paper published in the Journal of the Academy of Nutrition and Dietetics, the authors noted that dietary fiber should be used when developmentally appropriate (age 4-6 months) in the pres- ence of a colon. ${ }^{29}$ Pectin, a water soluble dietary fiber, may slow the motility of gastric contents and increase the contact of nutrients with the intestinal lumen. However, the dose used ( $1 \%-3 \%$ solution) is based on a single case series of 2 formerly premature infants who had small bowel resections. ${ }^{36}$ Drenckpohl et al ${ }^{37}$ documented the benefits of using stage 2 baby food green beans to infant feedings in a case series. After the addition of green beans to formula (4oz jar of green beans per 8-oz formula), stool consistency improved in all of the infants. The researchers concluded that the mixture of $32 \%$ soluble and $68 \%$ insoluble dietary fiber present in the green beans (2-3 g fiber per 4-oz jar) assisted in improving stool consistency.

While most dietitians did not report using a protocol for initiating oral/motor therapy, most centers do recommend therapy when appropriate. Oral aversion is common in patients who receive nutrition support for a prolonged 
period of time. Consequently, oral motor therapy and early oral feedings are important to the rehabilitation process. These therapies may also provide beneficial support for families who become frustrated with lack of progress with oral feeds. ${ }^{38}$ Although most centers did not report an exact time for initiation of complementary oral feedings, some use criteria to assess readiness or generally stated that they would begin oral feeds as soon as possible. The initiation of oral feeds as soon as developmentally and medically appropriate is important to prevent oral aversion. ${ }^{38}$ The first year of life is the most critical period for the development of oral feeding skills. ${ }^{33}$ Oral feeding promotes epidermal growth factor release from salivary glands and increases gastrointestinal secretion of trophic factors. ${ }^{33}$ Small bolus feedings by mouth (equal to or less than the volume tolerated continuously per hour) should be trialed to encourage development of swallowing. Solid food should be introduced at a developmentally appropriate age under the guidance of a feeding therapist. ${ }^{12}$ Unfortunately, no clinical studies have been conducted to identify the preferred time of initiation of complementary solid foods or the optimal oral diet for children with SBS. ${ }^{29}$ Current nutrition recommendations are subdivided by colon status. A highcarbohydrate $(50 \%-60 \%$ of energy), lower fat $(20 \%-30 \%$ of energy) diet may be indicated for patients with a colon while a higher fat ( $30 \%-40 \%$ of energy), lower carbohydrate (40\%-50\% of energy) diet may be preferred when the colon is absent. ${ }^{5}$ Complex carbohydrates may be better tolerated than simple sugars, and patients with a colon may need to avoid or restrict oxalate intake to decrease the risk of oxalate renal stones. ${ }^{5}$

Several components of nutrition management for children at risk for IFALD were consistent among all centers and were similar if not the same as those principles used for patients at risk for developing cholestasis. The literature related to minimization of soy-based fat emulsion $(\leq 1$ $\mathrm{g} / \mathrm{kg} / \mathrm{d}$ ) is primarily observational. Although restriction of IV fat emulsion has been shown to reduce total bilirubin levels in children with IFALD ${ }^{16}$ the effect of the accompanying caloric reduction on growth in the IF population is unknown. ${ }^{14}$ Levit et $\mathrm{al}^{39}$ conducted a clinical trial that examined the safety and efficacy in preventing IFALD using a low-dose soy-based fat emulsion $(1 \mathrm{~g} / \mathrm{kg} / \mathrm{d})$ vs a control dose $(\approx 3 \mathrm{~g} / \mathrm{kg} / \mathrm{d})$ in preterm infants $(\mathrm{n}=136)$ after 14 days of PN. The authors reported that after 28 days of life, no difference in growth or reduction of cholestasis was observed between the randomized groups. However, this was not a surgical population requiring prolonged PN support, and the determination of cholestasis $(\geq 15 \%$ of the total bilirubin at 28 days of life) differed from the definition used in other fat minimization studies (conjugated bilirubin $>2 \mathrm{mg} / \mathrm{dL}) .{ }^{15,16}$ Essential fatty acid deficiency was observed in infants with IFALD who were placed on a soy-based fat emulsion reduction protocol $(1 \mathrm{~g} / \mathrm{kg} / \mathrm{d}$ twice weekly) for a mean of 50 days (range, 11-712 days). ${ }^{16}$ Deficiencies were mild and resolved within 1-2 months after the number of days of fat infusion were increased. The authors noted the importance of monitoring markers of essential fatty acid deficiency during fat minimization and suggested that absolute values of linoleic and $\alpha$-linolenic acid be examined vs the triene/tetraene ratio, which is frequently used. ${ }^{16}$ Given the importance of dietary fat on infant brain development, there is concern about the effect of fat minimization on the long-term neurodevelopment of infants with IFALD treated with low-dose IV fat. Few studies have assessed this risk. However, preliminary findings at 1 institution showed that infants treated with IV fat emulsion reduction had mostly normal neurodevelopmental outcomes at ages ranging from 2-5 years. ${ }^{40}$ Another institution recently published data showing no adverse effect of low-dose IV soy-based fat emulsion on neurodevelopment or growth at 2 years of age in a cohort of 15 premature infants compared with 15 premature infants who received standard dosing. ${ }^{41}$

The use of $\omega-3$ or fish oil-based fat emulsions is associated with resolution of biochemical markers of IFALD ${ }^{42-44}$ but lacks rigorous clinical studies in the pediatric IF population. Puder et $\mathrm{al}^{45}$ conducted a trial of fish oil-based fat emulsion in 42 infants with SBS and cholestasis. Of the 38 patients who survived or were not transplanted, 19 $(50 \%)$ experienced reversal of cholestasis (direct bilirubin $\leq 2 \mathrm{mg} / \mathrm{dL}$ ). The fish oil-based fat emulsions are thought to improve liver function due to the anti-inflammatory properties of the $\omega-3$ fatty acids and improved triglyceride clearance. ${ }^{42}$ In addition, they lack the phytosterols of soybased fats, which are thought to be relatively hepatotoxic. ${ }^{42}$ However, there are reports of continued liver disease despite resolution of cholestasis, ${ }^{46-48}$ and similar reductions in cholestasis are achieved by restricting traditional soybased IV fats. Fish oil-based fat emulsions are not currently approved by the Food and Drug Administration (FDA) for use in the United States but remain available for use under research or compassionate use protocols. Alternatively, Smoflipid (Fresenius Kabi, Bad Homburg, Germany), an IV fat emulsion that contains soybean oil, medium-chain triglycerides, olive oil, and fish oil, is FDA approved for use in adults. Although the safety and efficacy of using Smoflipid in pediatric patients have not yet been established, ${ }^{49}$ randomized controlled trials have examined Smoflipid vs soy-based fat emulsion with encouraging results, including decreased serum $\gamma$-glutamyl transferase ${ }^{50}$ and total bilirubin ${ }^{51}$ in the Smoflipid groups. In a small retrospective review, conjugated bilirubin decreased within 2 weeks after a change to Smoflipid from a soy-based fat emulsion in children with IFALD. ${ }^{52}$

Reducing or removing trace elements from PN solutions is a proposed strategy to decrease the risk of IFALD. ${ }^{13}$ Since copper is eliminated via biliary excretion, parenteral intake of copper may need to be reduced when IFALD is present, 
while increased provision of copper may be necessary in patients with a jejunostomy or other biliary output. ${ }^{10,53} \mathrm{Of}$ note, copper deficiency has been reported with copper-free PN. ${ }^{53}$ Recent studies examining the practice of reducing or removing copper from PN solutions of cholestatic patients have shown that a standard intake of $20 \mathrm{mcg} / \mathrm{kg} / \mathrm{d}$ for infants may be safe, and it is suggested that copper levels be assessed prior to reducing or removing copper from PN solutions. ${ }^{54-56}$ Manganese supplementation may not be necessary for children with IFALD as manganese is a contaminant in $\mathrm{PN}$ solutions. ${ }^{38}$ Therefore, use of individual trace element preparations vs a packaged trace element preparation may be the best practice in patients with IFALD. ${ }^{10,38}$ Careful monitoring of trace element status when micronutrients are removed from $\mathrm{PN}$ is warranted.

Provision of EN in some form continues to be a significant component of the nutrition support practice for patients with IFALD. Expert opinion based on experience and available research seems to focus on advancing enteral feedings to promote intestinal adaptation and weaning PN support while maintaining proportional growth. EN is believed to promote intestinal adaptation by stimulating mucosal hyperplasia, gastrointestinal hormone secretion, and pancreaticobiliary secretions. ${ }^{1}$ These mechanisms may also protect against the development of IFALD by improving biliary flow and decreasing the risk of bacterial overgrowth, which may further inhibit bile secretions. ${ }^{23}$ Most experts agree on starting EN as early as medically feasible and advancing slowly while taking advantage of available strategies as previously discussed, including continuous feeds, refeeding of ostomy output into distal mucous fistula, and fiber supplementation. ${ }^{13,22,38}$

Our survey revealed considerable variability in laboratory test selection and monitoring frequency among pediatric IF practitioners. Most dietitians responding to the survey indicated the use of specific laboratory panels at defined intervals to address the reported high prevalence of micronutrient deficiencies in patients with pediatric IF. ${ }^{4,19,21,57}$ The laboratory monitoring practices of most centers are generally reflective of the evidence-based literature. Most centers routinely monitor urine sodium due to the known association of growth failure with a low urine sodium level, particularly in those patients with jejunostomies, ileostomies, and colostomies. ${ }^{58}$ Many centers have laboratory monitoring protocols, similar to published recommendations from children's hospitals with established IR centers, to address the high risk of micronutrient deficiency in their patient populations. ${ }^{12,57}$ Although infrequently mentioned by survey respondents, the monitoring of iodine status in pediatric IF patients has garnered much attention in the literature since the submission of survey results, particularly in light of numerous studies demonstrating the potential increased risk of iodine deficiency in pediatric patients requiring long-term PN supplementation.
Two case studies and 1 retrospective cohort analysis revealed varied use of iodine biomarkers (thyroid-stimulating hormone, T4, serum vs urine iodine) and varied frequency of monitoring ${ }^{59-61}$ in investigating iodine deficiency in their chronic $\mathrm{PN}$ pediatric patients. The high variability in laboratory test selection and monitoring frequency may be reflective of a lack of national guidelines. Our survey has revealed the importance of continual collaboration among centers to establish biochemical monitoring standards, particularly in the absence of the large numbers of subjects needed for wellexecuted clinical trials in this subspecialty area of practice. Areas in which collaboration may be beneficial include the following:

- Designating the relevant micronutrients for monitoring and the most reliable indicators (eg, erythrocyte vs plasma, serum vitamin B-12 or serum methylmalonic acid or both)

- Establishing the monitoring frequency and indications for any protocol variance (eg, intestinal anatomy, liver function, PN dependent vs nondependent)

- Facilitating monitoring across the inpatient/home health spectrum of care, particularly in regard to the management of parenteral trace element product shortages $^{62}$

The design of the practice survey has the advantage of permitting collection of data that might not be captured in a closed-ended questionnaire. However, this type of study survey also has several limitations. Questions are subject to individual interpretation (eg, what supplements do you typically recommend for patients with IF?), and specific components may not have been reported due to the openended format (eg, what laboratory tests do you routinely follow in patients with IF on PN?).

\section{Conclusion}

$\mathrm{EN}$ and PN management strategies in the presence and absence of cholestasis are relatively consistent among U.S. practitioners caring for children with IF. However, laboratory monitoring practices vary widely among centers. Although only half of the dietitians surveyed function as part of an organized IR program, interdisciplinary management and early referral of children dependent on PN to an IR program can result in positive outcomes, including cessation of PN support, accelerated growth, and improved survival. ${ }^{10,14}$ Multicenter clinical trials to identify best nutrition practices and to establish laboratory monitoring guidelines across the spectrum of care for children with IF would be optimal. Collaboration among centers should be encouraged considering the difficulty of conducting large-scale clinical trials in this population. Collaborative initiatives such as the Pediatric Intestinal Failure Section of ASPEN appear well 
positioned to pragmatically address the myriad variables affecting micronutrient status in pediatric IF patients and to issue evidence-based laboratory monitoring guidelines. Moreover, the section can foster collaboration and take an active role in conducting clinical research to determine best practices for enhancing intestinal adaptation and preventing or delaying nutrition support-related complications.

\section{Statement of Authorship}

A. M. Nucci contributed to the conception and design of the research, as well as the acquisition, analysis, and interpretation of the data. K. Ellsworth, A. Michalski, E. Nagel, and J. Wessel equally contributed to the design of the research. K. Ellsworth, A. Michalski, and E. Nagel contributed to the analysis and interpretation of the data. J. Wessel contributed to the interpretation of the data. A. M. Nucci, K. Ellsworth, A. Michalski, and E. Nagel drafted the manuscript. All authors critically revised the manuscript, gave final approval of the manuscript, and agree to be fully accountable for ensuring the integrity and accuracy of the work.

\section{References}

1. DiBaise JK, Young RJ, Vanderhoof JA. Intestinal rehabilitation and the short bowel syndrome: part 1. Am J Gastroenterol. 2004;99:13861395 .

2. Warner BW, Ziegler MM. Management of the short bowel syndrome in the pediatric population. Pediatr Clin North Am. 1993;40:1335-1350.

3. Barksdale EM, Stanford A. The surgical management of short bowel syndrome. Curr Gastroenterol Rep. 2002;4:229-237.

4. Wu J, Tang Q, Feng Y, et al. Nutrition assessment in children with short bowel syndrome weaned off parenteral nutrition: a long-term follow-up study. J Pediatr Surg. 2007;42:1372-1376.

5. DiBaise JK, Young RJ, Vanderhoof JA. Intestinal rehabilitation and the short bowel syndrome: Part 2. Am J Gastroenterol. 2004;99:18231832.

6. Duro D, Kamin D, Duggan C. Overview of pediatric short bowel syndrome. J Pediatr Gastroenterol Nutr. 2008;47:S33-S36.

7. Vanderhoof JA, Young RJ, Thompson JS. New and emerging therapies for short bowel syndrome in children. Pediatr Drugs. 2003;5(8): 525-531.

8. Goulet O, Sauvat F. Short bowel syndrome and intestinal transplantation in children. Curr Opin Clin Nutr Metab Care. 2006;9:304-313.

9. Kerner JA, ed. Manual of Pediatric Parenteral Nutrition. New York, NY: John Wiley; 1983.

10. Greene HL, Hambidge KM, Schanler R, Tsang RC. Guidelines for the use of vitamins, trace elements, calcium, magnesium, and phosphorus in infants and children receiving total parenteral nutrition: report of the Subcommittee on Pediatric Parenteral Nutrient Requirements from the Committee on Clinical Practice Issues of the American Society for Clinical Nutrition. Am J Clin Nutr. 1988;48:1324-1342.

11. Corkins MR, ed. The ASPEN Pediatric Nutrition Support Core Curriculum. 2nd ed. Silver Spring, MD: American Society for Parenteral and Enteral Nutrition; 2015.

12. Cole R, Kocoshis SA. Nutrition management of infants with surgical short bowel syndrome and intestinal failure. Nutr Clin Pract. 2013;28:421-428.

13. Mayer O, Kerner JA. Management of short bowel syndrome in postoperative very low birth weight infants. Semin Fetal Neonatal Med. 2017;22:49-56
14. Wales PW, Allen N, Worthington P, George D, Compher C, the American Society for Parenteral and Enteral Nutrition, Teitelbaum D. A.S.P.E.N. clinical guidelines: support of pediatric patients with intestinal failure at risk of parenteral nutrition-associated liver disease. JPEN J Parenter Enteral Nutr. 2014;38:538-557.

15. Sanchez SE, Braun LP, Mercer LD, Sherrill M, Stevens J, Javid PJ. The effect of lipid restriction on the prevention of parenteral nutritionassociated cholestasis in surgical infants. J Pediatr Surg. 2013;48:573578.

16. Cober MP, Killu G, Brattain A, Welch KB, Kunisaki SM, Teitelbaum DH. Intravenous fat emulsions reduction for patients with parenteral nutrition-associated liver disease. J Pediatr. 2012;160: 421-427.

17. Khan FA, Fisher JG, Sparks EA, et al. Preservation of biochemical liver function with low-dose soy-based lipids in children with intestinal failure-associated liver disease. J Pediatr Gastroenterol Nutr. 2015;60:375-377.

18. Nucci A, Burns RC, Armah T, et al. Interdisciplinary management of pediatric intestinal failure: a 10-year review of rehabilitation and transplantation. J Gastrointest Surg. 2008;12:429-436.

19. Ubesie AC, Kocoshis SA, Mezoff AG, Henderson CJ, Helmrath MA Cole CR. Multiple micronutrient deficiencies among patients with intestinal failure during and after transition to enteral nutrition. $J$ Pediatr. 2013;163:1692-1696.

20. Yang CJ, Duro D, Zurakowski D, Lee M, Jaksic T, Duggan C. High prevalence of multiple deficiencies in children with intestinal failure: a longitudinal study. J Pediatr. 2011;159:39-44.

21. Gonzalez HF, Perez NB, Malpeli A, Martinez MI, Buono BD, Viteri FE. Nutrition and immunological status in long-term follow up of children with short bowel syndrome. JPEN J Parenter Enteral Nutr. 2005;29:186-191.

22. Squires RH, Iyer KR. Intestinal failure. In: Corkins MR, ed. The ASPEN Pediatric Nutrition Support Core Curriculum. 2nd ed. Silver Spring, MD: American Society for Parenteral and Enteral Nutrition; 2015:427-440

23. Slicker J, Vermilyea S. Pediatric parenteral nutrition: putting the microscope on macronutrients and micronutrients. Nutr Clin Pract. 2009;24:481-486.

24. Werlin SL, Wyatt D, Camitta B. Effect of abrupt discontinuation of high glucose infusion rates during parenteral nutrition. J Pediatr. 1994; 124:441-444

25. Squires RH, Duggan C, Teitelbaum DH, et al. Natural history of pediatric intestinal failure: initial report from the pediatric intestinal failure consortium. J Pediatr. 2012;161:723-728.

26. Andorsky D, Lund D, Lillehei C, et al. Nutritional and other postoperative management of neonates with short bowel syndrome correlates with clinical outcomes. J Pediatr. 2001;139:27-33.

27. Vanderhoof J, Langnas A. Short-bowel syndrome in children and adults. Gastroenterology. 1997;113:1767-1778.

28. Ksiazyk J, Piena M, Keirkus J, Lyszkowska M. Hydrolyzed versus nonhydrolyzed protein diet in short bowel syndrome in children. $J$ Pediatr Gastroenterol Nutr. 2002;35:615-618.

29. Olieman J, Penning C, Ijsselstijn H. Enteral nutrition in children with short-bowel syndrome: current evidence and recommendations for the clinician. J Am Diet Assoc. 2010;110(3):420-426.

30. Parker P, Stroop S, Greene H. A controlled comparison of continuous intermittent feeding in the treatment of infants with intestinal disease. J Pediatr. 1981;99:360-364.

31. Joly F, Dray X, Corcos O, Barbot L, Kapel N, Messing B. Tube feeding improves intestinal absorption in short bowel syndrome patients. Gastroenterology. 2009;136:824-831.

32. Batra A, Beattie RM. Management of short bowel syndrome in infancy. Early Hum Dev. 2013;89:899-904. 
33. Goulet O, Olieman J, Ksiazyk J. Neonatal short bowel syndrome as a model of intestinal failure: physiological background for enteral feeding. Clin Nutr. 2013;32:162-171.

34. Batra A, Beattie RM. Management of short bowel syndrome in infancy. Early Hum Dev. 2013;89:899-904.

35. Nordgaard I, Hasen B, Mortensen P. Importance of colonic support for energy absorption as small-bowel failure proceeds. Am J Clin Nutr. 1996;65:222-231.

36. Hawkins R, Henry B, Gottschalk ME. Pectin supplemented enteral feedings in the treatment of short bowel syndrome in two infants. $J \mathrm{Am}$ Diet Assoc. 1995;95:A-28.

37. Drenckpohl D, Hocker J, Shareef M, Vegunta R, Colgan C. Adding dietary green beans resolves the diarrhea associated with bowel surgery in neonates: a case study. Nutr Clin Pract. 2005;20:674-677.

38. Wessel J, Kocoshis S. Nutritional management of infants with short bowel syndrome. Semin Perinatol. 2007;31:104-111.

39. Levit OL, Calkins KL, Gibson C, et al. Low-dose intravenous soybean oil emulsion for prevention of cholestasis in preterm neonates. JPEN J Parenter Enteral Nutr. 2016;40:374-382.

40. Blackmer AB, Warschausky S, Siddiqui S, et al. Preliminary findings of long-term neurodevelopment outcomes of infants treated with intravenous fat emulsion reduction for the management of parenteral nutrition-associated cholestasis. JPEN J Parenter Enteral Nutr. 2015;39:34-46.

41. Ong ML, Purdy IB, Levit OL, et al. Two-year neurodevelopment and growth outcomes for preterm neonates who received low-dose intravenous soybean oil [published online October 21, 2016]. JPEN J Parenter Enteral Nutr.

42. Gura K, Duggan C, Puder M, et al. Reversal of parenteral nutritionassociated liver disease in two infants with short bowel syndrome using parenteral fish oil: implications for future management. Pediatrics. 2006;118:e197-e201.

43. Gura K, Lee S, Valim C, et al. Safety and efficacy of a fish-oil-based fat emulsion in the treatment of parenteral nutrition-associated liver disease. Pediatrics. 2008;121:e678-e686.

44. Diamond IR, Sterescu A, Pencharz PB, et al. Changing the paradigm: omegaven for the treatment of liver failure in pediatric short bowel syndrome. J Pediatr Gastroenterol Nutr. 2009;48:209-215.

45. Puder M, Valim C, Meisel JA, et al. Parenteral fish oil improves outcomes in patients with parenteral nutrition associated liver injury. Ann Surg. 2009;250:395-402.

46. Soden JS, Lovell MA, Brown K, Partrick DA, Sokol RJ. Failure of resolution of portal fibrosis during omega-3 fatty acid lipid emulsion therapy in two patients with irreversible intestinal failure. $J$ Pediatr. 2010;156:327-331

47. Mercer DF, Hobson BD, Fischer RT, et al. Hepatic fibrosis persists and progresses despite biochemical improvement in children treated with intravenous fish oil emulsion. J Pediatr Gastroenterol Nutr. 2013;56:364369 .

48. Nandivada P, Chang MI, Potemkin AK, et al. The natural history of cirrhosis from parenteral nutrition-associated liver disease after resolution of cholestasis with parenteral fish oil therapy. Ann Surg. 2015;261:172-179.
49. Food and Drug Administration. SMOFLIPID. https://www.acce ssdata.fda.gov/drugsatfda_docs/label/2016/207648lbl.pdf. Published May, 2016. Accessed January 27, 2017.

50. Tomsits E, Pataki M, Tölgyesi A, Fekete G, Rischak K, Szollár L. Safety and efficacy of a lipid emulsion containing a mixture of soybean oil, medium-chain triglycerides, olive oil, and fish oil: a randomised, double-blind clinical trial in premature infants requiring parenteral nutrition. J Pediatr Gastroenterol Nutr. 2010;51:514521.

51. Goulet $\mathrm{O}$, Antébi $\mathrm{H}$, Wolf $\mathrm{C}$, et al. A new intravenous fat emulsion containing soybean oil, medium-chain triglycerides, olive oil, and fish oil: a single-center, double-blind randomized study on efficacy and safety in pediatric patients receiving home parenteral nutrition. JPEN J Parenter Enteral Nutr. 2010;34:485-495.

52. Attard MI, Patel N, Simpson J. Change from intralipid to SMOF lipid is associated with improved liver function in infants with $\mathrm{PN}$ associated liver disease. Arch Dis Child. 2012;97:A54-A55.

53. Hurwitz M, Garcia MG, Poole RL, Kerner JA. Copper deficiency during parenteral nutrition: a report of four pediatric cases. Nutr Clin Pract. 2004;19:305-308.

54. Frem J, Sarson Y, Sternberg T, Cole CR. Copper supplementation of cholestatic infants. J Pediatr Gastroenterol Nutr. 2010;50:650654.

55. Corkins MR, Martin VA, Szeszycki EE. Copper levels in cholestatic infants on parenteral nutrition. JPEN $J$ Parenter Enteral Nutr. 2013;37:92-96.

56. Blackmer AB, Bailey E. Management of copper deficiency in cholestatic infants: review of the literature and a case series. Nutr Clin Pract. 2013;28:75-86.

57. Chi-fu JY, Duro D, Zurakowski D, Lee M, Jaksic T, Duggan C. High prevalence of multiple micronutrient deficiencies in children with intestinal failure: a longitudinal study. J Pediatr. 2011;159: $39-44$.

58. Mansour F, Petersen D, De Coppi P, Eaton S. Effect of sodium deficiency on growth of surgical infants: a retrospective observational study. Pediatr Surg Int. 2014;30:1279-1284.

59. Mortensen M, Williamson N, David C, Hsu EK, Javid PJ, Horslen S. Iodine deficiency in a parenteral nutrition-dependent adolescent with intestinal pseudo-obstruction. JPEN J Parenter Enteral Nutr. 2016;40:730-733.

60. Golekoh MC, Cole CR, Jones NHY. Severe hypothyroidism from iodine deficiency associated with parenteral nutrition. JPEN J Parenter Enteral Nutr. 2016;40:1191-1193.

61. Santoro JD, Nespor C, Poole RL, Kerner JA. Iodine supplementation for pediatric patients receiving long-term parenteral nutrition. Nutr Clin Pract. 2016;31:245-249.

62. A.S.P.E.N. Clinical Practice Committee Shortage Subcommittee. Parenteral nutrition trace elements product shortage considerations. http:// www.nutritioncare.org/News/General_News/Parenteral_Nutrition_ Trace_Element_Product_Shortage_Considerations/. Updated July 26, 2016. Accessed January 13, 2017. 